\title{
Article
}

\section{Synergy between Two Metal Catalysts: A Highly Active Silica Supported Bimetallic W/Zr Catalyst for Metathesis of n-Decane}

Manoja K Samantaray, Raju Dey, Santosh Kavitake, Edy AbouHamad, Anissa Bendjeriou-Sedjerari, Ali Hamieh, and Jean-Marie Basset

J. Am. Chem. Soc., Just Accepted Manuscript • DOI: 10.1021/jacs.6b04307 • Publication Date (Web): 01 Jun 2016

Downloaded from http://pubs.acs.org on June 7, 2016

\section{Just Accepted}

"Just Accepted" manuscripts have been peer-reviewed and accepted for publication. They are posted online prior to technical editing, formatting for publication and author proofing. The American Chemical Society provides "Just Accepted" as a free service to the research community to expedite the dissemination of scientific material as soon as possible after acceptance. "Just Accepted" manuscripts appear in full in PDF format accompanied by an HTML abstract. "Just Accepted" manuscripts have been fully peer reviewed, but should not be considered the official version of record. They are accessible to all readers and citable by the Digital Object Identifier (DOI®). "Just Accepted" is an optional service offered to authors. Therefore, the "Just Accepted" Web site may not include all articles that will be published in the journal. After a manuscript is technically edited and formatted, it will be removed from the "Just Accepted" Web site and published as an ASAP article. Note that technical editing may introduce minor changes to the manuscript text and/or graphics which could affect content, and all legal disclaimers and ethical guidelines that apply to the journal pertain. ACS cannot be held responsible for errors or consequences arising from the use of information contained in these "Just Accepted" manuscripts. 


\title{
Synergy between Two Metal Catalysts: A Highly Active Silica Supported Bimetallic W/Zr Catalyst for Metathesis of $n$ - Decane
}

\author{
Manoja K. Samantaray, ${ }^{*}$ Raju Dey, Santosh Kavitake, Edy Abou-Hamad, Anissa Bendjeriou-Sedjerari, Ali Hamieh and Jean-Marie \\ Basset*
}

King Abdullah University of Science \& Technology, KAUST Catalysis Center (KCC), 23955-69oo Thuwal, Saudi Arabia.

\begin{abstract}
A well-defined, silica supported, bimetallic precatalyst $\left[\equiv \mathrm{Si}-\mathrm{O}-\mathrm{W}(\mathrm{Me})_{5} \equiv \mathrm{Si}-\mathrm{O}-\mathrm{Zr}(\mathrm{Np})_{3}\right](4)$ has been synthesized for the first time via successively grafting two organometallic complexes $\left[\mathrm{W}\left(\mathrm{CH}_{3}\right)_{6}(\mathbf{1})\right.$ followed by $\left.\mathrm{ZrNp}_{4}(\mathbf{2})\right]$ on a single silica support. Surprisingly, multiple quantum NMR characterization demonstrates that $\mathrm{W}$ and $\mathrm{Zr}$ species are in close proximity to each other. Hydrogenation of this bimetallic catalyst at room temperature showed the easy formation of Zirconium hydride, probably facilitated by tungsten hydride which was formed at this temperature. This bimetallic $\mathrm{W} / \mathrm{Zr}$ hydride precatalyst proved to be more efficient (TON: 1436) than the monometallic W hydride (TON: 650) in metathesis of $n$-decane at $150^{\circ} \mathrm{C}$. This synergy between $\mathrm{Zr}$ and $\mathrm{W}$ suggests that the slow step of alkane metathesis is the $\mathrm{C}-\mathrm{H}$ bond activation which occurs on $\mathrm{Zr}$. The produced olefin resulting from a $\beta-\mathrm{H}$ elimination undergoes easy metathesis on W.
\end{abstract}

\section{Introduction}

Alkanes which are the major constituents of petroleum, have gained intense research interest in the past few years. ${ }^{1,2-4}$ Despite recent advances in synthesizing welldefined, ${ }^{3,5}$ highly active catalysts for conversion of alkanes, a lot of aspects need to be addressed for the commercialization of these catalysts. One of them is improving the turnover number (TON). The primary constraint of alkane metathesis is the intrinsic low reactivity of $\mathrm{C}-\mathrm{H}$ and $\mathrm{C}-\mathrm{C}$ bonds of paraffin's. ${ }^{6}$ Alkane metathesis which is believed to be an ultimate solution to petrochemicals, consists of mainly three different chemical transformations namely, dehydrogenation of alkanes, olefin metathesis and hydrogenation of newly formed olefin. ${ }^{7}$ In 1969, Burnett and Hughes first discovered a dual tandem catalytic system comprising of $\mathrm{Pt} / \mathrm{Al}_{2} \mathrm{O}_{3}$ for dehydrogenation/hydrogenation and $\mathrm{WO}_{3} / \mathrm{SiO}_{2}$ for olefin metathesis reaction. ${ }^{8}$ Though this dual catalytic system had an impact on conversion of alkanes it suffers from high reaction temperature $\left(450^{\circ} \mathrm{C}\right)$. Recently, Goldman and Brookhart et al. have reported a tandem catalytic system which consists of two homogeneous catalysts for alkane metathesis at a lower temperature $\left(125-175{ }^{\circ} \mathrm{C}\right) .{ }^{9,10}$ While in 1997, using surface organometallic chemistry approach our group reported a well-defined, multifunctional, silica supported tantalum hydride catalyst, which is able to convert alkanes at much lower temperature $\left(150{ }^{\circ} \mathrm{C}\right) .{ }^{11}$ After this breakthrough various supported metal catalysts based on $\mathrm{Ta}$, Mo and $\mathrm{W}$ have been employed for the alkane metathesis. ${ }^{12-17}$ However, these catalytic systems showed little success in terms of efficiency, ${ }^{17-20}$ until the recent development of silica and silica-alumina supported $\mathrm{W}\left(\mathrm{CH}_{3}\right)_{6}$, which have been proved to be efficient in alkane metathesis with significantly higher TONs. ${ }^{21,22}$ In the quest for improving the efficiency in alkane metathesis reaction, we intentionally planned to move from a mono-metallic system (tungsten) to a bimetallic system, wherein another metal should be 1) very efficient for dehydrogenation and hydrogenation reaction at $150{ }^{\circ} \mathrm{C}$ and 2) it should not react with our parent metathesis catalyst. In this context it has been decided to use $\mathrm{Zr}(\mathrm{Np})_{4}$, since silica supported $\left[\equiv \mathrm{Si}-\mathrm{O}-\mathrm{Zr}(\mathrm{Np})_{3}\right]$ has already been reported by us, and was fully characterized at the molecular level using solid-state NMR, IR, elemental analysis and gas quantification methods. The corresponding $\left[(\equiv \mathrm{Si}-\mathrm{O}-)_{4-\mathrm{Z}} \mathrm{Zr}(\mathrm{H})_{\mathrm{x}}\right]$ is known to be very active in hydrogenolysis and $\mathrm{C}-\mathrm{H}$ bond activation reaction. ${ }^{23,24}$

Herein, we disclose the synthesis and molecular level characterization of a well-defined, silica supported, bimetallic precatalyst $\left[\equiv \mathrm{Si}-\mathrm{O}-\mathrm{W}\left(\mathrm{CH}_{3}\right)_{5} \equiv \mathrm{Si}-\mathrm{O}-\mathrm{Zr}(\mathrm{Np})_{3}\right](\mathbf{4})$ (Scheme 1) which upon thermal treatment at $100{ }^{\circ} \mathrm{C}$ transforms to a mixture of methylidyne species (5) (Scheme 2). The precatalyst 4 was converted into its corresponding hydrides, by the treatment with hydrogen at room temperature 6 and at high temperature, 7 respectively (Scheme 3). To evaluate its catalytic activity towards alkanes, we choose $n$-decane as substrate for comparison with our previous studies which showed that maximum TON of 350 can be achieved by using silica-alumina supported $\mathrm{W}\left(\mathrm{CH}_{3}\right)_{6}$ system. While these bimetallic catalysts 4, 6 and 7 showed TON (1005), (1436) and (1250) respectively, representing a significant increase in activity for the metathesis of $n$-decane. Notably, we have never ob- 
served any decomposition of the bimetallic catalyst during the grafting onto the silica support.

\section{Results and Discussion}

\section{Preparation and characterization of $\left[\equiv \mathrm{Si}-\mathrm{O}-\mathrm{W}(\mathrm{Me})_{5}\right.$ $\left.\equiv \mathrm{Si}-\mathrm{O}-\mathrm{Zr}(\mathrm{Np})_{3}\right]$ (4) on $\mathrm{SiO}_{2-7 \mathrm{oo}}$ :}

Individual grafting of $\mathrm{W}\left(\mathrm{CH}_{3}\right)_{6}(\mathbf{1})$ and $\mathrm{ZrNp}_{4}(\mathbf{2})$ on silica has already been reported by us, and was fully characterized at the molecular level using solid-state NMR, IR, elemental analysis and gas quantification methods. ${ }^{21,25}$ For the first time we anchor the homogeneous organometallic species 1 followed by $\mathbf{2}$ on a single surface $\left[\left(\mathrm{SiO}_{2}\right)_{700}\right.$ which contain $0.3 \pm 0.1 \mathrm{mmol}$ silanol groups per gram] at $-40{ }^{\circ} \mathrm{C}$ and $25{ }^{\circ} \mathrm{C}$ respectively, under an inert atmosphere of argon (Scheme 1).

Scheme 1: Synthesis of supported $\left[\equiv \mathrm{Si}-\mathrm{O}-\mathrm{W}(\mathrm{Me})_{5} \equiv \mathrm{Si}-\right.$ $\left.\mathrm{O}-\mathrm{Zr}(\mathrm{Np})_{3}\right]$ (4)

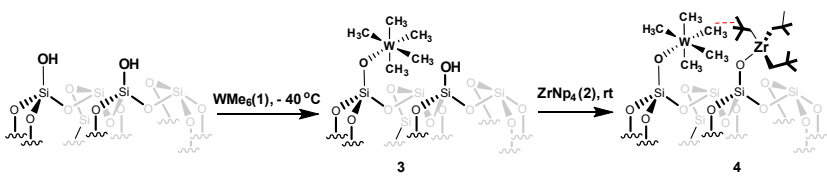

The elemental analysis shows that 4 contains $1.13 \mathrm{wt}$. \% of tungsten, 0.37 wt. \% of carbon $(\mathrm{C} / \mathrm{W}$ ratio $=5+/-0.1$, expected value of 5 ), and $1.9 \mathrm{wt} \%$ of zirconium, $3.73 \mathrm{wt} \%$ of carbon $(\mathrm{C} / \mathrm{Zr}$ ratio $=14.94+/$ - o.1, expected value of 15$)$.

An IR spectrum of $\mathbf{4}$ showed the complete disappearance of the bands at $3747 \mathrm{~cm}^{-1}$, which are associated with isolated and geminal silanols. For 4, two new groups of bands in the region of 3018-2864 and 1465 and $1365 \mathrm{~cm}^{-1}$ were observed. These are assigned to $v(\mathrm{CH})$ and $\delta(\mathrm{CH})$ vibrations of the methyl and the neopentyl ligands bonded to tungsten and zirconium (SI Figure $\mathrm{S}_{1}$ ).

Further spectroscopic analyses of $\mathbf{4}$ were also conducted with solid-state NMR. The ${ }^{1} \mathrm{H}$ magic-angle spinning (MAS) solid-state NMR spectrum of $\mathbf{4}$ displays three signals at 2.0, 1.2 and 0.9 ppm (Figure $1 \mathrm{~A}$ ). Strong autocorrelation peaks were observed at 0.9 and $2.0 \mathrm{ppm}$ in double-quantum (DQ) (1.8 and $4.0 \mathrm{ppm}$ in indirect dimensions) and in triple-quantum (TQ) (2.7 and 6.0 ppm in indirect dimensions) NMR experiments under $22 \mathrm{kHz}$ MAS as shown in Figure $1 \mathrm{~B}$ and $1 \mathrm{C}$ respectively. This strong auto-correlation peak is attributed to the methyl groups, whereas the peak at $\mathbf{1 . 2} \mathrm{ppm}$ auto-correlate in DQ (2.4 Ppm indirect dimensions) but not in TQ which corresponds to methylene. In addition, and very surprisingly, we also observe a correlations outside the diagonal between the methyls of $\mathrm{W}$ (2.0 ppm) and methyls of $\mathrm{Zr}-\mathrm{Np}$ (o.9 ppm) which confirms both the moiety are unexpectedly very close to each other in space. The ${ }^{13} \mathrm{C} C \mathrm{CP} / \mathrm{MAS}$ NMR spectrum of an enriched sample of $\mathbf{4}$ (please note that only tungsten methyls are 50\% enriched) showed three peaks at 82, 94 and 32 ppm (Figure 1D) which corre- late respectively with the proton resonances at 2.0, 1.2, and $0.9 \mathrm{ppm}$ as indicated in the $2 \mathrm{D}^{1} \mathrm{H}^{13} \mathrm{C}$ HETCOR NMR spectrum recorded with a contact time of $0.2 \mathrm{~ms}$, assigned to methyls of $\mathrm{W}$ and neopentyls of zirconium (Figure $1 \mathrm{E}$ ). The ${ }^{1} \mathrm{H}$ and ${ }^{13} \mathrm{C}$ chemical shifts are similar to those observed in the solution NMR spectra of molecular species 1 and 2 (SI Figure $\mathrm{S}_{2}, \mathrm{~S}_{3}, \mathrm{~S}_{4}, \mathrm{~S}_{5}$, and $\mathrm{S} 6$ ). Note that the grafting of the mixture $\mathbf{1}$ and $\mathbf{2}$ on oxide supports could result in the formation of monopodal or bipodal grafted species due to strained silica ring defects produced after thermal dehydroxylation. However, ${ }^{1} \mathrm{H}$ and ${ }^{13} \mathrm{C}$ solid-state NMR spectroscopy did not indicate the presence of signal at or near o.o ppm which cancels the probability of methyl or neopentyl transfer to an adjacent silicon atom of silica and hence ruled out the formation of bipodal species $\left[(\equiv \mathrm{Si}-\mathrm{O})_{2} \mathrm{~W}(\mathrm{Me})_{4}(\equiv \mathrm{Si}-\mathrm{O})_{2} \mathrm{Zr}(\mathrm{Np})_{2}\right][\equiv \mathrm{Si}-\mathrm{R}, \mathrm{R}=\mathrm{Me}$ or $\mathrm{Np}$ ]

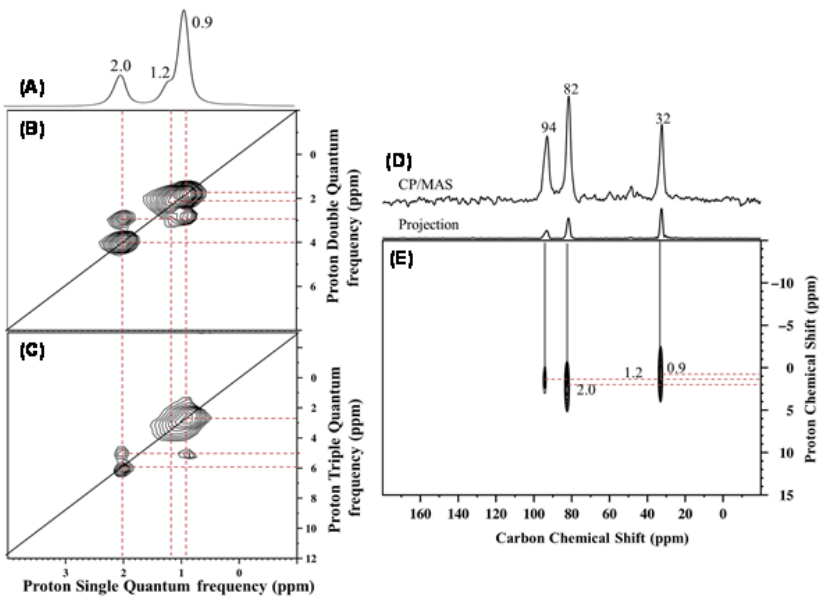

Figure 1. (A) One-dimensional (1D) ${ }^{1} \mathrm{H}$ MAS solid-state NMR spectrum of 4 acquired at $600 \mathrm{MHz}(14.1 \mathrm{~T})$ with a $22 \mathrm{kHz}$ MAS frequency, a repetition delay of $5 \mathrm{~s}$, and 8 scans. (B) Two-dimensional (2D) ${ }^{1} \mathrm{H}^{-1} \mathrm{H}$ double-quantum (DQ)/singlequantum (SQ) and (C) ${ }^{1} \mathrm{H}-{ }^{1} \mathrm{H}$ triple-quantum (TQ)/SQ NMR spectra of 4 (both acquired with 32 scans per $t_{1}$ increment, $5 \mathrm{~s}$ repetition delay, 128 individual $t_{1}$ increments). (D) ${ }^{13} \mathrm{C}$ CP/MAS NMR spectrum of 4 (acquired at $9.4 \mathrm{~T}\left(\zeta_{0}\left({ }^{1} \mathrm{H}\right)=400\right.$ $\mathrm{MHz}$ ) with a $10 \mathrm{kHz}$ MAS frequency, 10000 scans, a $4 \mathrm{~s}$ repetition delay, and a 2 ms contact time. Exponential line broadening of $80 \mathrm{~Hz}$ was applied prior to Fourier transformation. (E) $2 \mathrm{D}^{1} \mathrm{H}^{13} \mathrm{C} \mathrm{CP} / \mathrm{MAS}$ dipolar HETCOR spectrum of 4 (acquired at $9.4 \mathrm{~T}$ with $10 \mathrm{kHz}$ MAS frequency, 3000 scans per $t_{1}$ increment, a $4 \mathrm{~s}$ repetition delay, 64 individual $t_{1}$ increments and a $0.2 \mathrm{~ms}$ contact time). For all spectra depicted here only $\mathrm{W}-\mathrm{CH}_{3}$ in 4 was $50 \%{ }^{13} \mathrm{C}$ labelled.

Synthesis of the well-defined $\mathrm{W} / \mathrm{Zr}$ bimetallic catalyst on silica surface $\left[\equiv \mathrm{Si}-\mathrm{O}-\mathrm{W}(\mathrm{Me})_{5} \equiv \mathrm{Si}-\mathrm{O}-\mathrm{Zr}(\mathrm{Np})_{3}\right](4)$ was our main purpose to enhance the catalytic properties of the catalyst. To observe the effect of the bimetallic system on catalysis, initially, we employed 4 for the metathesis of $n$-decane. To our expectation it proved to be very active in $n$-decane metathesis with TON 1005 as compared to 150 TON using $3^{22}$ clearly indicating the cooperative role of $\mathrm{Zr}$ in the metathesis of $n$-decane. 
Observation of tungsten carbyne species 5 via thermal treatment of precursor 4

The excellent activity observe using catalyst precursor 4 might be due to the formation of tungsten methylidene species in the surface as it is covered by two metal complexes. We heated supported species 4 , which is $50 \%$ enrich ${ }^{13} \mathrm{C}$ of tungsten methyl from $298 \mathrm{~K}$ to $345 \mathrm{~K}$. Upholding the temperature at $345 \mathrm{~K}$ for 6 hours several peaks were observed (SI Figure $\mathrm{S}_{7}$ ). The ${ }^{1} \mathrm{H}$ NMR resonances of neopentyl of zirconium at 0.9 and $1.2 \mathrm{ppm}$ did not change, whereas the peak at $2.0 \mathrm{ppm}$ diminished and several others signals were observed. The NMR spectra of the converted material suggested that the products are $\mathrm{W}$-methyl/methylidyne species $\mathbf{5}$ (Scheme $\mathbf{2}$ and Figure 2). The ${ }^{1} \mathrm{H}$ NMR of the converted material exhibits several new signals at 0.0, 1.0, 1.1, 4.1, and $7.6 \mathrm{ppm}$ (Figure 2 and SI figure $\mathrm{S}_{7}$ ). The signals at 1.0, 1.1, and $4.1 \mathrm{ppm}$ autocorrelate in $2 \mathrm{D}$ DQ and $\mathrm{TQ}{ }^{1} \mathrm{H}-{ }^{1} \mathrm{H}$ homonuclear dipolar correlation spectra, and are assigned to different methyl groups of tungsten (Figures $2 \mathrm{~B}$ and $2 \mathrm{C}$ ).

Scheme 2: Thermal treatment of species 4 leads to formation of tungsten methylidyne on surface

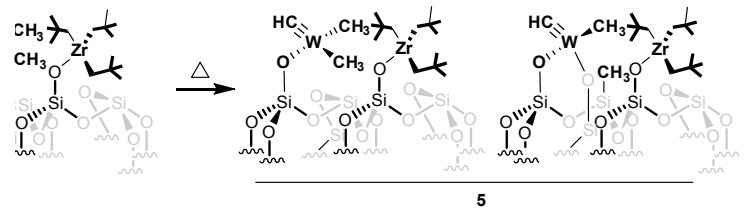

Along with this observation we also observe that the proton resonance at $7.6 \mathrm{ppm}$ displays no auto-correlation in the DQ and TQ spectra (Figure $2 \mathrm{~B}$ and $2 \mathrm{C}$ ). The broad signal at $0.0 \mathrm{ppm}$ is assigned to methane and methyl groups transferred to silica (i.e., $\equiv \mathrm{SiMe}$, suggesting a bipodal $\mathrm{W} /$ silica), which is supported by an autocorrelation in $\mathrm{DQ}$ and TQ (Figure $2 \mathrm{~B}$ and $2 \mathrm{C}$ ).

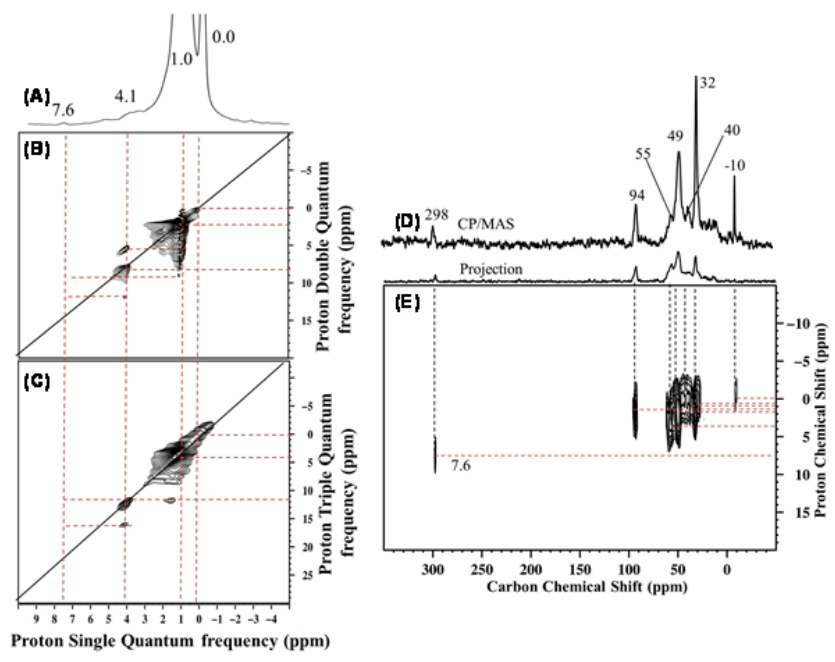

Figure 2. (A) $1 \mathrm{D} 1 \mathrm{H}$ spin-echo MAS solid-state NMR spectrum of $[(\equiv \mathrm{SiO}) \times \mathrm{xW}(\equiv \mathrm{CH}) \mathrm{Mey}]$ after maintaining the temper- ature of $95 \% 13 \mathrm{C}$ labelled 2 at $345 \mathrm{~K}$ for 6 hours (acquired on a $600 \mathrm{MHz}$ NMR spectrometer under a $20 \mathrm{kHz}$ MAS spinning frequency, number of scans $=8$, repetition delay $=5 \mathrm{~s}$ ). (B) $2 \mathrm{D} 1 \mathrm{H}-1 \mathrm{H}$ DQ and (C) $1 \mathrm{H}-1 \mathrm{H}$ TQ (acquired on a $600 \mathrm{MHz}$ NMR spectrometer under $22 \mathrm{kHz}$ MAS spinning frequency with a back-to-back recoupling sequence, number of scans = 128 , repetition delay $=5 \mathrm{~s}$, number of $\mathrm{t}_{1}$ increments $\left.=128\right)(\mathrm{D})$ ${ }_{13} \mathrm{C}$ CP/MAS NMR spectrum (10 $\mathrm{kHz}$ MAS at the same field as above, number of scans $=20000$, repetition delay $=4 \mathrm{~s}$, contact time $=2 \mathrm{~ms}$, line broadening $=8 \mathrm{o} \mathrm{Hz})(\mathrm{E}) 2 \mathrm{D} 1 \mathrm{H}-13 \mathrm{C}$ CP/MAS dipolar HETCOR NMR spectrum acquired with short contact times of $0.2 \mathrm{~ms}$ under $10 \mathrm{kHz}$ MAS, number of scans per increment $=3000$, repetition delay $=4 \mathrm{~s}$, number of t 1 increments $=32$, line broadening $=8 \mathrm{o} \mathrm{Hz}$ ).

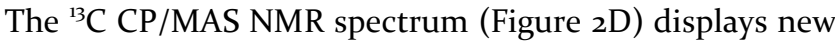
signals at 40,49 , and $55 \mathrm{ppm}$, a signal at $298 \mathrm{ppm}$ at high frequency and a signal at -10 ppm at low frequency in addition to the stable signals at 32 and $94 \mathrm{ppm}$. Additionally, the $2 \mathrm{D}{ }^{1} \mathrm{H}^{13} \mathrm{C}$ HETCOR NMR spectrum (Figure $2 \mathrm{E}$ ) with a short contact time $(0.2 \mathrm{~ms})$ shows a correlation between the methyl protons (1.1 and 1.0 ppm) to that of carbon atoms (49 and $40 \mathrm{ppm}$ ) respectively, and a correlation between the methyl protons centred at $4.0 \mathrm{ppm}$ with the carbon at $55 \mathrm{ppm}$ allows the assignment of the carbon-proton pairs to the individual methyl groups. Furthermore, the strong correlation between the carbon and proton signals at $298 \mathrm{ppm}$ and $7.6 \mathrm{ppm}$, respectively, strongly supports the assignment of a methylidyne moiety $(\mathrm{W} \equiv \mathrm{CH})$ (based on our previous studies on $\left.[\equiv \mathrm{SiO}) \mathrm{W}(\equiv \mathrm{CH}) \mathrm{Me}_{2}\right]$ (Figure $\left.2 \mathrm{E}\right) \cdot{ }^{21}$ In addition, two strong correlations observed in $2 \mathrm{D}^{1} \mathrm{H}-{ }^{13} \mathrm{C}$ HETCOR proton at 0.9 and $1.2 \mathrm{ppm}$ to that of carbon atoms 32 and 94 ppm respectively which is coming from the methylene and methyl moiety of the neopentyl attached to zirconium (Figure 1 and $2 \mathrm{E}$ ). Furthermore, a correlation in DQ/SQ NMR correlation spectrum between the $\equiv \mathrm{SiCH}_{3}$ at o.o ppm and the methyl groups at $4.1 \mathrm{ppm}$ supports transfer of a methyl group to the silica and suggests the formation of bipodal species $\left({ }^{13} \mathrm{C}: 55 \mathrm{ppm} ;{ }^{1} \mathrm{H}: 4.1 \mathrm{ppm}\right)$ (Scheme 2). Since no correlation with the other two methyl groups is observed, these two inequivalent methyl groups $\left({ }^{13} \mathrm{C}: 44\right.$ and $40 \mathrm{ppm} ;{ }^{1} \mathrm{H}: 1.4$ and $1.1 \mathrm{ppm}$ ) can be assigned to the monopodal species. The methyl groups of both the species of $\mathbf{5}$ correlate with the methylidyne moiety as observed in both DQ and TQ NMR experiments (Figures $2 \mathrm{~B}$ and ${ }_{2} \mathrm{C}$ ).

We could not observe the formation of tungsten methylidene during thermal decomposition stage but we observed very high reactivity in metathesis reaction. Therefore, we assumed that we might have been generating zirconium hydride during the reaction. To validate our assumption we thought to mix both on two different sili$\mathrm{ca}_{700}$ supports tungsten and zirconium hydride separately and carry out our catalytic reaction. Surprisingly, after mixing both supported hydrides and carrying out the catalytic reaction we observed slightly increase in the rate of the reaction, with TON of 898 instead of 650 for W hydride alone. However, the TON was observed to be slightly lower than that of 4 (TON 1005) and 5 (TON 963). This 
clearly indicates that having $\mathrm{W}$ and $\mathrm{Zr}$ both together on the same support favours the metathesis reaction. With this hypothesis we thought we would synthesize both tungsten and zirconium hydride on the single surface and use them for the catalytic reaction and hence the comparison of the catalyst.

Hydrogenation of species $4\left[\equiv \mathrm{Si}-\mathrm{O}-\mathrm{W}(\mathrm{Me})_{5} \equiv \mathrm{Si}-\mathrm{O}\right.$ $\left.\operatorname{Zr}(\mathrm{Np})_{3}\right]$ at different temperatures and their catalytic activity:

Our previous study showed that we can generate tungsten hydride at room temperature because of its reactive nature towards hydrogen. ${ }^{26}$ We thought to react 4 [ $[\equiv \mathrm{Si}-\mathrm{O}$ $\left.\mathrm{W}(\mathrm{Me})_{5} \equiv \mathrm{Si}-\mathrm{O}-\mathrm{Zr}(\mathrm{Np})_{3}\right]$ with hydrogen at room temperature to generate tungsten hydride-zirconium neopentyl on silica without forming silicon hydride and then to heat it at $150{ }^{\circ} \mathrm{C}$ to generate both the hydride species. In contrast, while passing dry hydrogen through our sample and monitoring the generation of hydride surprisingly, we observed tungsten and zirconium hydride simultaneously at room temperature (Scheme 3 and Figure 3 ).

Scheme 3. Formation of the bi-metallic hydride species at different temperatures

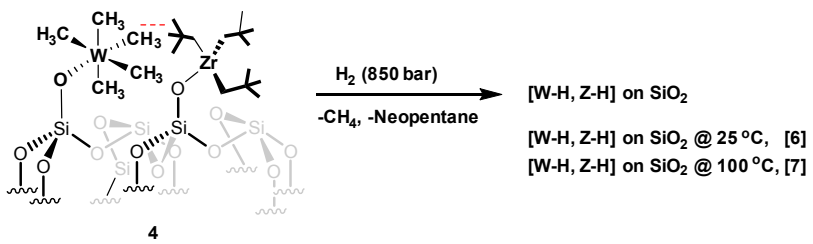

Infrared spectrum shows that the peak intensity decreases at 3018 to $2863 \mathrm{~cm}^{-1}$ and at the same time four new peaks are observed in the region of 2256 to $1632 \mathrm{~cm}^{-1}$. The peaks at 2200, 2256 corresponds to silicon mono and bis hydride [m, $v(\mathrm{SiH})$ and $\left.v\left(\mathrm{SiH}_{2}\right)\right]^{27}$, and the other two peaks at 1957 and $1632 \mathrm{~cm}^{-1}$ represents tungsten hydride $v\left(\mathrm{WH}_{\mathrm{x}}\right)$ and zirconium hydride $v\left(\mathrm{ZrH}\right.$ and $\left.\mathrm{ZrH}_{2}\right)$ respectively (Figure 3). ${ }^{1} \mathrm{H}$ NMR showed 4 major peaks at 1.0, 4.5, 10.9 and $13.3 \mathrm{ppm}$. The broad peak at 1.0 ppm comes from the unreacted neopentyl groups of zirconium. The new broad peak at $4.5 \mathrm{ppm}$ is ascribed to $\mathrm{SiH}, \mathrm{SiH}_{2}$ and peak at 10.9 ppm assigned as zirconium mono hydride as it is already described in the literature. ${ }^{27}$ Along with these peaks we also observe another peak at $13.3 \mathrm{ppm}$ we believe it might be because of formation of $\mathrm{W}-\mathrm{H}_{\mathrm{x}}$ as literature report showed that the peak corresponding to $\mathrm{W}-\mathrm{H}$ can be observed in the region of $12-16 \mathrm{ppm}^{26,28-30}$ (SI-Figure S8). To completely remove the neopentyl group from zirconium we heated 4 at $100{ }^{\circ} \mathrm{C}$ for 12 hours in the presence of 850 mbar of hydrogen (Figure 3 and SI-Figure S1o).

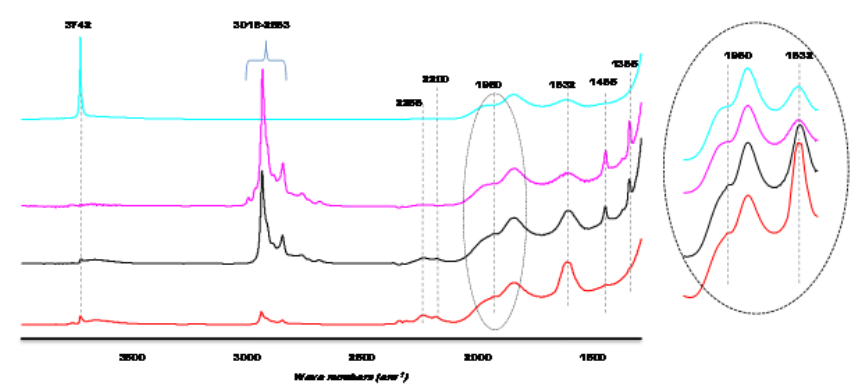

Figure 3. IR spectra of $\mathrm{SiO}_{2-700}$ (blue), after grafting $\mathrm{W}\left(\mathrm{CH}_{3}\right)_{6}$ and $\mathrm{Zr}(\mathrm{Np})_{4}$ (magenta 4 ), Reaction of 4 with dry hydrogen at room temperature (black 6) and after hydrogenolysis at 100 ${ }^{\circ} \mathrm{C}$ temperature (red 7)

After continuing the heating at $100{ }^{\circ} \mathrm{C}$ for 12 hours the peak intensities decreases considerably at 3018 to 2863 $\mathrm{cm}^{-1}$ along with the complete disappearance of the peaks at 1465 and $1365 \mathrm{~cm}^{-1}$ which are supposed to be $\delta\left(\mathrm{CH}_{2}\right.$, $\mathrm{CH}_{3}$ ) of zirconium neopentyl group. Along with the disappearance of these peaks four new distinct peaks were observed at 2200, 22561957 and $1632 \mathrm{~cm}^{-1}$ respectively, which are assigned as silicon mono and bis hydride $(\mathrm{m}$, $v(\mathrm{SiH})$ and $v\left(\mathrm{SiH}_{2}\right), v(\mathrm{WHx})$ and zirconium hydride $v(\mathrm{ZrH}$ and $\left.\mathrm{ZrH}_{2}\right){ }^{27}$ It is also characterized by ${ }^{1} \mathrm{H}$ NMR the peaks at $4.5 \mathrm{ppm}$ is assigned to $\mathrm{SiH}, \mathrm{SiH}_{2}$ and peaks at 10.4 and 12.2 ppm assigned to $\left(\mathrm{Zr}-\mathrm{H}\right.$ and $\left.\mathrm{ZrH}_{2}\right)$ respectively as it is already known in literature. The peak at $13.3 \mathrm{ppm}$ assigned as $\mathrm{WH}_{\mathrm{x}}$ according to the literature report. ${ }^{26,28-30}$ Formation of both hydrides on a single surface was observed for the first time along with the formation of more intense silicon hydride peak at higher temperature (Figure 3 and SI Figure S1o). Interestingly, the catalytic results were excellent with these catalysts with the highest TON of 1436 ever observed for a well-defined supported system (Table 1 ).

Table 1. $n$-decane metathesis reaction: activity (TON) of precursors 4,6 and 7 at $150^{\circ} \mathrm{C}$.

\begin{tabular}{|l|c|c|c|}
\hline Catalyst precursor & $\begin{array}{c}\text { n-decane/ } \\
\text { W(Ratio) }\end{array}$ & $\begin{array}{c}\text { n-decane/ } \\
\mathbf{Z r} \text { (Ratio) }\end{array}$ & TON $\left({ }^{\text {a }}\right)$ \\
\hline$\left[\mathrm{W}-\mathrm{H} @ 25^{\circ} \mathrm{C}\right]$ & 1981 & -- & 650 \\
\hline$\left[\mathrm{Zr}-\mathrm{H} @ 100{ }^{\circ} \mathrm{C}\right]$ & -- & 1234 & 32 \\
\hline $\begin{array}{l}{\left[\equiv \mathrm{Si}-\mathrm{O}-\mathrm{W}(\mathrm{Me})_{5} \equiv \mathrm{Si}-\mathrm{O}-\right.} \\
\left.\mathrm{Zr}(\mathrm{Np})_{3}\right](\mathbf{4})\end{array}$ & 4182 & 1234 & 1005 \\
\hline$\left[\mathrm{W}-\mathrm{H}, \mathrm{Zr}-\mathrm{H} @ 25^{\circ} \mathrm{C}\right](6)$ & 4182 & 1234 & 1436 \\
\hline$\left[\mathrm{W}-\mathrm{H}, \mathrm{Zr}-\mathrm{H} @ 100^{\circ} \mathrm{C}\right](7)$ & 4182 & 1234 & 1250 \\
\hline
\end{tabular}

(a) Turnover number (TON) is expressed in mol of $n$ decane converted per mol of tungsten (W)

Evaluation of the Catalytic Activity of 4, 6 and 7 for $n$ decane metathesis

Despite the synthesis of well-defined group $\mathrm{V}$ and group VI metal alkyls and their corresponding hydrides on various oxide supports and their use for alkane metathesis reaction, we did not improve previously significantly the 
efficiency in terms of TONs. With this observation of bimetallic effect we believed it would be possible to increase the efficiency and hence TON of the catalyst.

Herein, we show the dramatic influence of an auxiliary metal in a bi-metallic system for $n$-decane metathesis. Specifically, we choose supporting zirconium hydrides which are well known for low temperature $\mathrm{C}-\mathrm{H}$ bond activation reaction. In this context we prepared and fully characterized the precatalysts $\mathbf{4}, \mathbf{6}$ and $\mathbf{7}$. We tested these catalysts in the $n$-decane metathesis reaction and compared their catalytic activity with the existing parent silica supported catalyst (Table-1).

In a typical experiment $n$-decane $(5.14 \mathrm{mmol})$ and appropriate amount of precatalyst $\mathbf{4}, \mathbf{6}$, and 7 ( $n$-decane/W $=$ 4182, and $n$-decane $/ \mathrm{Zr}=1234$ ) were mixed inside a glove box in a glass ampoule. The ampoule was frozen outside using liquid nitrogen and sealed under vacuum. Each ampoule was heated at $150{ }^{\circ} \mathrm{C}$ for a specific time. At the end of the reaction the ampules were taken outside, frozen under liquid nitrogen and then quenched with dichloromethane. The reaction mixture was filtered, the filtrate was collected and was analyzed by GC and GC-MS. GC chromatogram clearly indicates a wide range of distribution of $n$-alkanes ranging from $\mathrm{C}_{3}$ to $\mathrm{C}_{34}$ (isometathesis) (Figure 4 for precatalyst 6 and SI Figure S11 and S12 for precatalyst 4 and 7 ). NMR studies on the crude sample indicates the formation of only linear alkanes with $<1 \%$ branched alkanes.

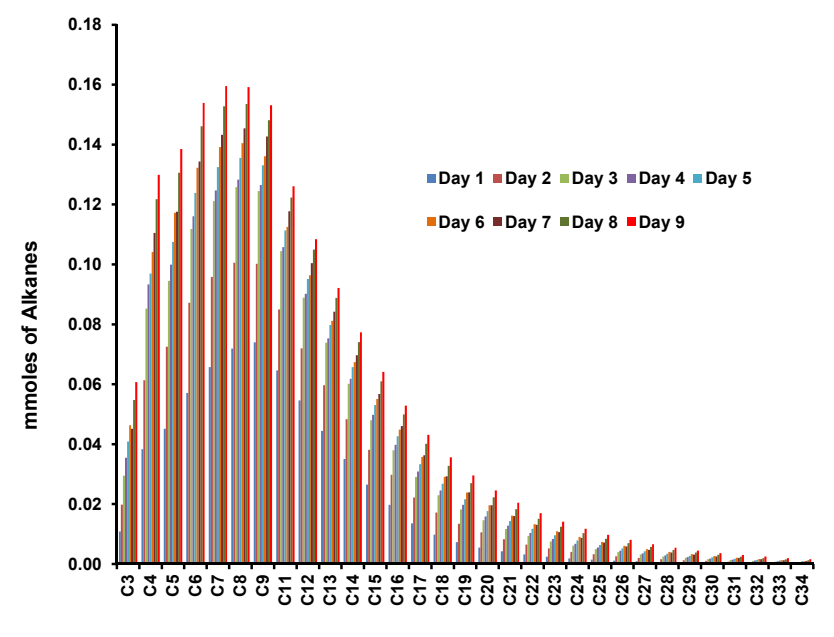

n-Alkanes

Figure 4. Products distribution of $n$-decane metathesis catalysed by precatalyst 6

A much wider distribution of products were observed using species $\mathbf{4}^{\mathbf{7}}$, implies that the double bond isomerization of the olefin intermediate is faster than the overall elementary steps of alkane metathesis (chain walking process). ${ }^{31}$ Additionally, this product distribution also suggests that hydride species of $\mathrm{W}$ and $\mathrm{Zr}$ are responsible for double bond migration (via a secondary alkyl), which is being formed during the course of the reaction. Besides, alkane distribution clearly indicates that the formation of lower alkanes is predominant as compared to higher al- kanes (Figure 4). Similar distribution was already observed by Brookhart and Goldman. ${ }^{10}$

Kinetic studies of $n$-decane metathesis catalyzed by precatalyst 4,6 , and 7 were carried out at $150^{\circ} \mathrm{C}$. The conversion vs time curve (Figure 5 ) indicates that the rate of the reaction is higher for the species $\mathbf{6}$ and $\mathbf{7}$ as compared to species $\mathbf{4}$ which is understandable as species $\mathbf{6}$ and $\mathbf{7}$ are hydride species generated from species 4. A steady start was observed in the case of species $\mathbf{6}$ and $\mathbf{7}$ at the beginning of the reaction and at the end precatalyst $\mathbf{6}$ was found to be more active and remained stable up to 9 days with the highest conversion of $34 \%$ and TON of 1436 (Figure 5). The better performance of species 6 is believed to be due to formation of a lower amount of $\mathrm{Si}-\mathrm{H}$ while treatment with hydrogen leads to less bipodal species as compared to species 7 (Figure 3 ).

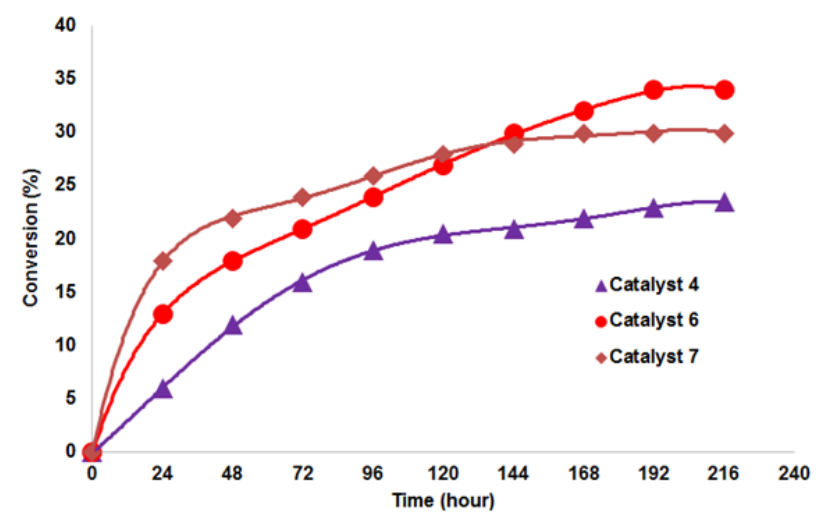

Figure 5. Conversion versus time for the metathesis of $n$ decane catalyzed by $\left[\equiv \mathrm{Si}-\mathrm{O}-\mathrm{W}(\mathrm{Me})_{5} \equiv \mathrm{Si}-\mathrm{O}-\mathrm{Zr}(\mathrm{Np})_{3}\right](\mathbf{4})$ (৫),[W-H,Zr-H@25 $\left.{ }^{\circ} \mathrm{C}\right](6)(\bullet)$ and [W-H,Zr-H@10o $\left.{ }^{\circ} \mathrm{C}\right](7)(\diamond)$. Reaction conditions: batch reactor, species 4,6 and 7 , reactant to tungsten ratio 4182 , with loading of $\mathrm{W}$ (1.1 wt\%, $n$-decane (1.0 mL, $5.14 \mathrm{mmol})$ at $150{ }^{\circ} \mathrm{C}$

We observed that the bimetallic $\mathrm{W} / \mathrm{Zr}$ system is excellent for the metathesis of $n$-decane, even though only supported zirconium produce lower metathesis products under identical conditions (conversion $3 \%$ TON 32) (Table 1). While choosing zirconium to compile with tungsten for better metathesis result we envisioned that as supported zirconium is better catalyst for $\mathrm{C}-\mathrm{H}$ activation reaction and it might help our tungsten ( which is well known for alkane metathesis catalyst) to improve the reactivity and TON. Additionally, to prove our point we carried out a reaction of $n$-decane with tert-butylethylene (TBE) using supported zirconium at $150^{\circ} \mathrm{C}$. At the end of the reaction GC and GC-MS data shows that the formation of olefin which metathesize with excess TBE and gives 2,2-dimethyldec-3-ene. This above experiment confirms that in $\mathrm{W} / \mathrm{Zr}$ bimetallic system the rate and conversion is higher because zirconium forms olefin and $\mathrm{W}$ does the metathesis and at the end reduction of the new olefins to alkanes. 


\section{Conclusion}

For the first time two chemically compatible organometallic complexes were grafted on a single surface (silica70o) without interfering with each other. The surface complex was fully characterized by advanced solid state NMR, IR elemental analysis and gas quantification methods. It was observed that at least $50 \%$ of zirconium should be nearby tungsten (strong autocorrelation of the methyls on both the system in ${ }^{1} \mathrm{H}-{ }^{1} \mathrm{H}$-double and triple quantum spectra). Furthermore, the precatalysts 4, and hydrogen treated species 6 and 7 are proved to be an excellent catalyst for the metathesis of $n$-decane with very high TONs as compared to their counterparts (silica supported tungsten methyl and zirconium neopentyls). This opens up new perspectives for the synthesis of various supported bimetallic systems via SOMC approach to improve the alkane metathesis reaction.

\section{- EXPERIMENTAL SECTION}

\section{General procedure:}

All experiments were carried out by using standard Schlenk and glovebox techniques under an inert argon atmosphere. The syntheses and the treatments of the surface species were carried out using high vacuum lines (< $10^{-5}$ mbar) and glove-box techniques. Pentane was distilled from a $\mathrm{Na} / \mathrm{K}$ alloy under argon and dichloromethane from $\mathrm{CaH}_{2}$. Both solvents were degassed through freeze-pump-thaw cycles. $\mathrm{SiO}_{2-700}$ prepared from Aerosil silica from Degussa (specific area of $200 \mathrm{~m}^{2} / \mathrm{g}$ ), which were partly dehydroxylated at $700{ }^{\circ} \mathrm{C}$ under high vacuum $\left(<10^{-5} \mathrm{mbar}\right.$ ) for $24 \mathrm{~h}$ to give a white solid having a specific surface area of $190 \mathrm{~m}^{2} / \mathrm{g}$ and containing $0.5-0.7$ $\mathrm{OH} / \mathrm{nm}^{2}$. Hydrogen and propane were dried and deoxygenated before use by passage through a mixture of freshly regenerated molecular sieves $(3 \AA)$ and $R_{3-15}$ catalysts (BASF). IR spectra were recorded on a Nicolet 6700 FT-IR spectrometer by using a DRIFT cell equipped with $\mathrm{CaF}_{2}$ windows. The IR samples were prepared under argon within a glovebox. Typically, 64 scans were accumulated for each spectrum (resolution $4 \mathrm{~cm}^{-1}$ ). Elemental analyses were performed at Mikroanalytisches Labor Pascher (Germany) and ACL KAUST.

GC measurements were performed with an Agilent $7890 \mathrm{~A}$ Series (FID detection). Method for GC analyses: Column HP-5; 3om length x 0.32mm ID x $0.25 \mu \mathrm{m}$ film thickness; Flow rate: $1 \mathrm{~mL} / \mathrm{min}\left(\mathrm{N}_{2}\right)$; split ratio: 50/1; Inlet temperature: $250{ }^{\circ} \mathrm{C}$, Detector temperature: $250{ }^{\circ} \mathrm{C}$; Temperature program: $40{ }^{\circ} \mathrm{C}(3 \mathrm{~min}), 40-250^{\circ} \mathrm{C}\left(12{ }^{\circ} \mathrm{C} / \mathrm{min}\right), 250{ }^{\circ} \mathrm{C}(3$ min), $250-300{ }^{\circ} \mathrm{C}\left(10{ }^{\circ} \mathrm{C} / \mathrm{min}\right), 300{ }^{\circ} \mathrm{C}(3 \mathrm{~min})$; $n$-decane retention time: $\mathrm{tR}=9.6$

GC-MS measurements were performed with an Agilent 7890A Series coupled with Agilent 5975C Series. GC/MS equipped with capillary column coated with non-polar stationary phase $\mathrm{HP}_{-5} \mathrm{MS}$ was used for molecular weight determination and identification that allowed the separation of hydrocarbons according to their boiling points differences. GC response factors of available $C_{7}-C_{10} n$ alkanes standards were calculated as an average of three independent runs. The plot of response factor versus $n$ alkanes carbon number was determined and a linear correlation was found, then we extrapolated the response factors for other $n$-alkanes. Organometallic complex 1 and 2 and their corresponding silica supported complexes were prepared according to literature procedures. . $^{21,32-34}$

\section{Liquid State Nuclear Magnetic Resonance Spectros- copy:}

All liquid state NMR spectra were recorded on Bruker Avance $600 \mathrm{MHz}$ spectrometers. All chemical shifts were measured relative to the residual ${ }^{1} \mathrm{H}$ or ${ }^{13} \mathrm{C}$ resonance in the deuterated solvent: $\mathrm{CD}_{2} \mathrm{Cl}_{2}$, and $\mathrm{C}_{6} \mathrm{D}_{6}$.

\section{Solid State Nuclear Magnetic Resonance Spectrosco- py:}

One dimensional ${ }^{1} \mathrm{H}$ MAS and ${ }^{13} \mathrm{C} \mathrm{CP} / \mathrm{MAS}$ solid state NMR spectra were recorded on Bruker AVANCE III spectrometers operating at $400 \mathrm{MHz}$ or $600 \mathrm{MHz}$ resonance frequencies for ${ }^{1} \mathrm{H}$. $400 \mathrm{MHz}$ experiments employed a conventional double resonance $4 \mathrm{~mm} \mathrm{CP} / \mathrm{MAS}$ probe, while experiments at $600 \mathrm{MHz}$ utilized a $3.2 \mathrm{~mm} \mathrm{HCN}$ triple resonance probe. In all cases the samples were packed into rotors under inert atmosphere inside gloveboxes. Dry nitrogen gas was utilized for sample spinning to prevent degradation of the samples. NMR chemical shifts are reported with respect to the external references TMS and adamantane. For ${ }^{13} \mathrm{C} C \mathrm{P} / \mathrm{MAS}$ NMR experiments, the following sequence was used: 900 pulse on the proton (pulse length $2.4 \mathrm{~s}$ ), then a cross-polarization step with a contact time of typically $2 \mathrm{~ms}$, and finally acquisition of the ${ }^{13} \mathrm{C}$ signal under high power proton decoupling. The delay between the scans was set to $4 \mathrm{~s}$ to allow the complete relaxation of the ${ }^{1} \mathrm{H}$ nuclei and the number of scans ranged between 10 ooo - 20 ooo for ${ }^{13} \mathrm{C}$ and was 8 for ${ }^{1} \mathrm{H}$. An exponential apodization function corresponding to a line broadening of $8 \mathrm{o} \mathrm{Hz}$ was applied prior to Fourier transformation.

The $2 \mathrm{D}{ }^{1} \mathrm{H}^{13} \mathrm{C}$ heteronuclear correlation (HETCOR) solid state NMR spectroscopy experiments were conducted on a Bruker AVANCE III spectrometer operating at $400 \mathrm{MHz}$ using a $3.2 \mathrm{~mm}$ MAS probe. The experiments were performed according to the following scheme: 900 proton pulse, tr evolution period, $\mathrm{CP}$ to ${ }^{13} \mathrm{C}$, and detection of the ${ }^{13} \mathrm{C}$ magnetization under TPPM decoupling. For the crosspolarization step, a ramped radio frequency (RF) field centered at $75 \mathrm{kHz}$ was applied to the protons, while the ${ }^{13} \mathrm{C}$ channel RF field was matched to obtain optimal signal. A total of 32 or 64 t1 increments with 3 ooo scans each were collected. The sample spinning frequency was 10 $\mathrm{kHz}$. Using a short contact time ( $0.2 \mathrm{~ms}$ ) for the CP step, the polarization transfer in the dipolar correlation exper- 
iment was verified to be selective for the first coordination sphere about the tungsten, that is to lead to correlations only between pairs of attached ${ }^{1} \mathrm{H}-{ }^{13} \mathrm{C}$ spins $(\mathrm{C}-\mathrm{H}$ directly bonded).

\section{${ }^{1} \mathbf{H}-{ }^{1} \mathbf{H}$ multiple-quantum spectroscopy:}

Two-dimensional double-quantum (DQ) and triplequantum (TQ) experiments were recorded on a Bruker AVANCE III spectrometer operating at $600 \mathrm{MHz}$ with a conventional double resonance $3.2 \mathrm{~mm} \mathrm{CP} / \mathrm{MAS}$ probe, according to the following general scheme: excitation of DQ coherences, t1 evolution, z-filter, and detection. The spectra were recorded in a rotor synchronized fashion in t1 by setting the t1 increment equal to one rotor period. One cycle of the standard back-to-back (BABA) recoupling sequences was used for the excitation and reconversion period. ${ }^{35}$ Quadrature detection in w1 was achieved using the States-TPPI method. An MAS frequency of $20 \mathrm{kHz}$ was used. The $90^{\circ}$ proton pulse length was $2.5 \mu$ s, while a recycle delay of $5 \mathrm{~s}$ was used. A total of 128 t1 increments with 32 or 128 scans per each increment were recorded. The DQ frequency in the w1 dimension corresponds to the sum of two single quantum (SQ) frequencies of the two coupled protons and correlates in the w2 dimension with the two corresponding proton resonances. ${ }^{27}$ The TQ frequency in the w1 dimension corresponds to the sum of the three SQ frequencies of the three coupled protons and correlates in the w2 dimension with the three individual proton resonances. Conversely, groups of less than three equivalent spins will not give rise to diagonal signals in this spectrum.

Preparation of supported complex 4 on $\mathrm{SiO}_{2-700}$ : A solution of $\mathbf{1}$ in pentane (30 $\mathrm{mg}, 0.11 \mathrm{mmol}$ ) was reacted with $2.0 \mathrm{~g}$ of Aerosil $\mathrm{SiO}_{2-700}$ at $-40{ }^{\circ} \mathrm{C}$ for 3 hours; it was filtered washed with pentane $(3 \times 20 \mathrm{~mL})$ and dried for 20 minutes under vacuum. The resulting light yellow powder was transferred to another double Schlenk and to that a pentane solution of excess $2(225 \mathrm{mg}, 0.6 \mathrm{mmol})$ was added at room temperature and reaction was continued at that temperature for another 3 hours. At the end of the reaction, the resulting light yellow solid was washed with pentane $(3 \times 20 \mathrm{~mL})$ and dried under dynamic vacuum (< $10^{-5}$ Torr, $\left.1 \mathrm{~h}\right)$. IR data $\left(\mathrm{cm}^{-1}\right): 3018-2863,1465,1365, .{ }^{1} \mathrm{H}$ solid-state NMR (400 MHz): $\delta(\mathrm{ppm})=2.0\left(\mathrm{~W}-\mathrm{CH}_{3}\right), 1.2(\mathrm{Zr}-$ $\left.\mathrm{CH}_{2}\right)$, o.9 $\left(-\mathrm{CH}_{2}\left(\mathrm{CH}_{3}\right)_{3}\right) .{ }^{13} \mathrm{C} \mathrm{CP} /$ MAS solid-state NMR (100 $\mathrm{MHz}): \delta(\mathrm{ppm})=94.0\left(\mathrm{Zr}-\mathrm{CH}_{2}\right), 82.0\left(\mathrm{~W}-\mathrm{CH}_{3}\right), 32.0(\mathrm{Zr}-$ $\left.\mathrm{CH}_{2}\left(\mathrm{CH}_{3}\right)_{3}\right)$. Elemental analysis: W: 0.29-1.13 \%wt, $\mathrm{Zr}: 1.95^{-}$ 1.90 \%wt C: 3.96-4.10 \%wt. C/W ratio obtained 5.0 +/-0.1 (expected was 5) C/Zr ratio obtained 15.0 +/-0.1 (expected was 15).

Synthesis of 5: In a glass reactor, $1.0 \mathrm{~g}$ of 4 was taken and heated at $90{ }^{\circ} \mathrm{C}$ (ramped at $60{ }^{\circ} \mathrm{C} / \mathrm{h}$ ) for 12 hours to produce a light gray coloured powder which is a mixture of the monopodal and bipodal species, 5. IR data $\left(\mathrm{cm}^{-1}\right)$ : 2949-2708, 1467, 1365. ${ }^{1} \mathrm{H}$ solid-state NMR (400 MHz): $\delta$ $(\mathrm{ppm})=0.0\left(\mathrm{~s}, \mathrm{Si}-\mathrm{CH}_{3}\right), 0.9\left(\mathrm{~s}, \mathrm{Zr}-\mathrm{CH}_{2}-\left(\mathrm{CH}_{3}\right)_{3}\right)$, 1.0 (s, W$\left.\mathrm{CH}_{3}\right), 1.1\left(\mathrm{~s}, \mathrm{Zr}-\mathrm{CH}_{2}\right), 1.2\left(\mathrm{~s}, \mathrm{~W}-\mathrm{CH}_{3}\right), 4.1\left(\mathrm{~s}, \mathrm{~W}-\mathrm{CH}_{3}\right), 7.6(\mathrm{~s}$,
$\mathrm{W} \equiv \mathrm{CH}) .{ }^{13} \mathrm{C} \mathrm{CP} / \mathrm{MAS}$ solid-state NMR (10o MHz): $\delta(\mathrm{ppm})$ $=-10\left(\mathrm{Si}-\mathrm{CH}_{3}\right)$, $32.0\left(\mathrm{Zr}-\mathrm{CH}_{2}\left(\mathrm{CH}_{3}\right)_{3}\right), 40\left(\mathrm{~s}, \mathrm{~W}-\mathrm{CH}_{3}\right), 49(\mathrm{~s}$, $\left.\mathrm{W}-\mathrm{CH}_{3}\right), 55\left(\mathrm{~s}, \mathrm{~W}-\mathrm{CH}_{3}\right)$, $94.0\left(\mathrm{Zr}-\mathrm{CH}_{2}\right), 298(\mathrm{~s}, \mathrm{~W} \equiv \mathrm{CH})$. Elemental analysis: W: 0.29 \%wt, Zr: 2.0 \%wt C: 3.8 \%wt. $\mathrm{C} / \mathrm{W}$ ratio obtained $3.0+/$-0.1 (expected was 3) $\mathrm{C} / \mathrm{Zr}$ ratio obtained 14.3 +/-0.1 (expected was 15).

Synthesis of 6: A sample of 4 (100 $\mathrm{mg})$ and dry $\mathrm{H}_{2}(850$ mbar) was added in a batch reactor and allowed the reaction to continue at room temperature for 10 hour. The light gray product was evacuated at high vacuum and characterized through ${ }^{1} \mathrm{H}$ NMR and IR and elemental analysis. IR data $\left(\mathrm{cm}^{-1}\right)$ : 2949-2708, 1960, 1632, 1467, 1365. ${ }^{1} \mathrm{H}$ solid-state NMR (40o MHz): $\delta(\mathrm{ppm})=1.0\left(\mathrm{br}, \mathrm{Zr}^{-} \mathrm{CH}_{2}-\right.$ $\left.\left(\mathrm{CH}_{3}\right)_{3}\right), 4.5$ (br, Si-H, Si-H $\left.{ }_{2}\right), 10.9$ (br, Zr-H $), 13.3$ (s, W$\left.\mathrm{H}_{\mathrm{x}}\right) .{ }^{13} \mathrm{C} \mathrm{CP} / \mathrm{MAS}$ solid-state NMR (100 MHz): $\delta(\mathrm{ppm})=$ 32.0 $\left(\mathrm{Zr}-\mathrm{CH}_{2}\left(\mathrm{CH}_{3}\right)_{3}\right)$, 94.o $\left(\mathrm{Zr}-\underline{\mathrm{C}} \mathrm{H}_{2}\right)$. Elemental analysis: W: 0.29 \%wt, Zr: 1.98 \%wt C: $1.91 \% w t$ C/W ratio obtained $7.3+/$-o.1.

Synthesis of 7: In a reactor tube $100 \mathrm{mg}$ of 4 was taken and to this dry $\mathrm{H}_{2}$ (850 mbar) was added and heated at $150{ }^{\circ} \mathrm{C}$ for 12 hours. At the end of the reaction a dark gray powder was obtained this product was characterized by ${ }^{1} \mathrm{H}$ NMR, IR and elemental analysis. IR data $\left(\mathrm{cm}^{-1}\right): 2949-$ 2708 196o, 1632,. ${ }^{1} \mathrm{H}$ solid-state NMR (40o MHz): $\delta$ (ppm) $=1.0\left(\mathrm{br}, \mathrm{Zr}-\mathrm{CH}_{2}-\left(\mathrm{CH}_{3}\right)_{3}\right), 1.9$ (s, S-OH), 4.5 (br, Si-H, Si$\mathrm{H}_{2}$ ), 10.4 (br, $\left.\mathrm{Zr}-\mathrm{H}\right), 12.2\left(\mathrm{br}, \mathrm{Zr}-\mathrm{H}_{2}\right), 13.3\left(\mathrm{~s}, \mathrm{~W}-\mathrm{H}_{\mathrm{x}}\right)$. Elemental analysis: W: 0.29 \%wt, $\mathrm{Zr}: 2.01$ \%wt C: $0.21 \% w t$. $\mathrm{C} / \mathrm{W}$ ratio obtained $0.79+/-0.1$.

\section{Reaction of TBE with [ $\left.=\mathrm{Si}-\mathrm{O}-\mathrm{Zr}(\mathrm{Np})_{3}\right]$ :}

To understand the role of the second metal (here zirconi$\mathrm{um})$ we react silica supported zirconium $\left[\equiv \mathrm{Si}-\mathrm{O}-\mathrm{Zr}(\mathrm{Np})_{3}\right]$ with $n$-decane and TBE and heated it at $150{ }^{\circ} \mathrm{C}$. At the end of the reaction GC and GC MS data confirms the formation of olefin (2,2-dimethyldec-3-ene) from $n$-decane.

\section{Typical Procedure for n-Decane Metathesis Reac- tions:}

A mixture of 4,6 and $7\left(1.23 \times 10^{-3} \mathrm{mmol}\right.$ of $\left.\mathrm{W}\right)$ and dry $n$ decane $(5.14 \mathrm{mmol})$ were mix inside the glove box. The ampoules were sealed under vacuum, immersed in an oil bath and heated at $150{ }^{\circ} \mathrm{C}$. At the end of the reaction, the ampoules were frozen using liquid nitrogen. Then, the catalytic run was quenched by addition of fixed amount of $\mathrm{CH}_{2} \mathrm{Cl}_{2}$ and after filtration the resulting solution is analysed by GC and GC/MS. For kinetic studies, each analysis represents an independent run.

\section{ASSOCIATED CONTENT}

Supporting Information. Supporting information contain IR spectra of $\mathbf{4}$, solution NMR spectra of $\mathbf{1}, \mathbf{2}$, solid-state NMR spectra of $\mathbf{6}$ and 7 and variable temperature of 4. "This material is available free of charge via the Internet at http://pubs.acs.org." 


\section{AUTHOR INFORMATION}

\section{Corresponding Author}

* jeanmarie.basset@kaust.edu.sa

manoja.samantaray@kaust.edu.sa

\section{Funding Sources}

This publication is based upon work supported by the King Abdullah University of Science and Technology (KAUST) Office of Sponsored Research (OSR)

\section{ACKNOWLEDGMENT}

The authors acknowledge the KAUST Nuclear Magnetic Resonance Core Lab and analytical core lab (ACL) for the analysis of the sample. This publication is based upon work supported by the King Abdullah University of Science and Technology (KAUST) Office of Sponsored Research (OSR).

\section{REFERENCES}

(1) Jeremie, D. A. P; Basset, J. M. Acc. Chem. Res. 2016, 49, 664

(2) Basset, J. M.; Coperet, C.; Soulivong, D.; Taoufik, M.; Cazat, J. T. Acc. Chem. Res. 2010, 43, 323.

(3) Coperet, C.; Comas-Vives, A.; Conley, M. P.; Estes, D. P.; Fedorov, A.; Mougel, V.; Nagae, H.; Nunez-Zarur, F.; Zhizhko, P. A. Chem. Rev. 2o16, 116, 323.

(4) Haibach, M. C.; Kundu, S.; Brookhart, M.; Goldman, A. S. Acc. Chem. Res. 2012, 45, 947.

(5) Basset, J. M.; Coperet, C.; Soulivong, D.; Taoufik, M.; Thivolle-Cazat, J. Angew. Chem. Int. Ed. 2oo6, 45, 6082.

(6) Labinger, J. A.; Bercaw, J. E. Nature 2002, 417, 507.

(7) Basset, J. M.; Coperet, C.; Lefort, L.; Maunders, B. M.; Maury, O.; Le Roux, E.; Saggio, G.; Soignier, S.; Soulivong, D.; Sunley, G. J.; Taoufik, M.; Thivolle-Cazat, J. J. Am. Chem. Soc. 2005, 127, 8604 .

(8) Burnett, R. L.; Hughes, T. R. J. Catal. 1973, 31, 55.

(9) Goldman, A. S.; Roy, A. H.; Huang, Z.; Ahuja, R.; Schinski, W.; Brookhart, M. Science 20o6, 312, 257.

(10) Huang, Z.; Rolfe, E.; Carson, E. C.; Brookhart, M.; Goldman, A. S.; El-Khalafy, S. H.; MacArthur, A. H. R. Adv. Synth. Catal. 2010, 352, 125.

(11) Vidal, V.; Theolier, A.; ThivolleCazat, J.; Basset, J. M. Science 1997, 276, 99.

(12) Szeto, K. C.; Hardou, L.; Merle, N.; Basset, J. M.; ThivolleCazat, J.; Papaioannou, C.; Taoufik, M. Catal. Sci. Tech. 2012, 2, 1336.

(13) Coperet, C.; Maury, O.; Thivolle-Cazat, J.; Basset, J. M. Angew. Chem. Int. Ed. 2001, 40, 2331.

(14) Le Roux, E.; Taoufik, M.; Baudouin, A.; Coperet, C.; Thivolle-Cazat, J.; Basset, J. M.; Maunders, B. M.; Sunley, G. J. Adv. Synth. Catal. 2007, 349, 231.
(15) Taoufik, M.; Le Roux, E.; Thivolle-Cazat, J.; Coperet, C.; Basset, J. M.; Maunders, B.; Sunley, G. J. Top. Catal. 2oo6, $40,65$.

(16) Le Roux, E.; Chabanas, M.; Baudouin, A.; de Mallmann, A.; Coperet, C.; Quadrelli, E. A.; Thivolle-Cazat, J.; Basset, J. M.; Lukens, W.; Lesage, A.; Emsley, L.; Sunley, G. J. J. Am. Chem. Soc. 2004, 126, 13391.

(17) Chen, Y.; Abou-hamad, E.; Hamieh, A.; Hamzaoui, B.; Emsley, L.; Basset, J. M. J. Am. Chem. Soc. 2015, 137, 588.

(18) Blanc, F.; Coperet, C.; Thivolle-Cazat, J.; Basset, J. M. Angew. Chem. Int. Ed. 2006, 45, 6201.

(19) Saint-Arroman, R. P.; Chabanas, M.; Baudouin, A.; Coperet, C.; Basset, J. H.; Lesage, A.; Emsley, L. J. Am. Chem. Soc. 2001, $123,3820$.

(20) Le Roux, E.; Taoufik, M.; Coperet, C.; de Mallmann, A.; Thivolle-Cazat, J.; Basset, J. M.; Maunders, B. M.; Sunley, G. J. Angew. Chem. Int. Ed. 2005, 44, 6755.

(21) Samantaray, M. K.; Callens, E.; Abou-Hamad, E.; Rossini, A. J.; Widdifield, C. M.; Dey, R.; Emsley, L.; Basset, J. M. J. Am. Chem. Soc. 2014, 136, 1054.

(22) Samantaray, M. K.; Dey, R.; Abou-Hamad, E.; Hamieh, A.; Basset, J. M. Chem. Eur. J. 2015, 21, 6100.

(23) Corker, J.; Lefebvre, F.; Lecuyer, C.; Dufaud, V.; Quignard, F.; Choplin, A.; Evans, J.; Basset, J. M. Science 1996, 271, 966.

(24) Besedin, D. V.; Ustynyuk, L. Y.; Ustynyuk, Y. A.; Lunin, V. V. Top. Catal. 2005, 32, 47.

(25) Quignard, F.; Lecuyer, C.; Choplin, A.; Olivier, D.; Basset, J. M. J. Mol. Catal. 1992, 74, 353.

(26) Maity, N.; Barman, S.; Callens, E.; Samantaray, M. K.; AbouHamad, E.; Minenkov, Y.; D'Elia, V.; Hoffman, A. S.; Widdifield, C. M.; Cavallo, L.; Gates, B. C.; Basset, J. M. Chem. Sci. 2016, 7, 1558.

(27) Rataboul, F.; Baudouin, A.; Thieuleux, C.; Veyre, L.; Coperet, C.; Thivolle-Cazat, J.; Basset, J. M.; Lesage, A.; Emsley, L. J. Am. Chem. Soc. 2004, 126, 12541.

(28) Gregson, D.; Howard, J. A. K.; Nicholls, J. N.; Spencer, J. L.; Turner, D. G. J. Chem. Soc. Chem. Commun. 1980, 572.

(29) Schrock, R. R.; Shih, K. Y.; Dobbs, D. A.; Davis, W. M. J. Am. Chem. Soc. 1995, 117, 6609.

(30) Dobbs, D. A.; Schrock, R. R.; Davis, W. M. Inorg. Chim. Acta. 1997, 263, 171.

(31) Domski, G. J.; Rose, J. M.; Coates, G. W.; Bolig, A. D.; Brookhart, M. Prog. Polym. Sci. 2007, 32, 30.

(32) Pfennig, V.; Seppelt, K. Science 1996, 271, 626.

(33) Shortlan.Aj; Wilkinso.G J. Chem. Soc., Dalton Trans. 1973, 872.

(34) Saint-Arroman, R. P.; Basset, J. M.; Lefebvre, F.; Didillon, B. Appl. Catal. A Gen. 2005, 290, 181.

(35) Sommer, W.; Gottwald, J.; Demco, D. E.; Spiess, H. W. J. Magn. Reson. 1995, 113, 131. 


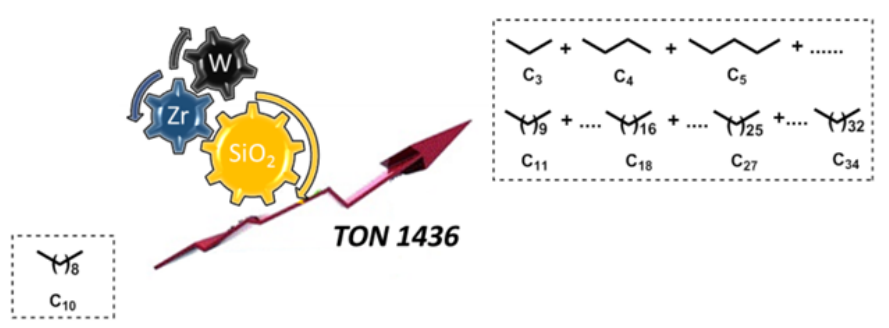

